\title{
Effect of Blend Ratio on the Properties of Polystyrene/Acrylonitrile Butadiene Styrene/Carbon Black (PS/ABS/CB) Conductive Materials
}

\author{
Ming Yeng Chan, Pei Leng Teh* and Cheow Keat Yeoh \\ School of Materials Engineering, Universiti Malaysia Perlis, \\ 02600 Jejawi, Perlis \\ *Corresponding author: plteh@unimap.edu.my
}

Published online: 30 April 2019

To cite this article: Ming Yeng Chan, Pei Leng Teh and Cheow Keat Yeoh (2019). Effect of blend ratio on the properties of polystyrene/acrylonitrile butadiene styrene/carbon black (PS/ABS/CB) conductive materials. Journal of Engineering Science, 15, 63-75, https:// doi.org/10.21315/jes2019.15.6.

To link to this article: https://doi.org/10.21315/jes2019.15.6

\begin{abstract}
This research focused the effect of different polystyrene/acrylonitrile butadiene styrene (PS/ABS) blend ratio (0:100, 20:80, 40:60, 50:50, 60:40, 80:20 and 100:0) on the properties of polystyrene/acrylonitrile butadiene styrene/carbon black (PS/ABS/CB) conductive polymer composites (CPCs). Materials were produced through melt blending by using Brabender Plastograph internal mixer. The effect of PS/ABS blend ratio at fixed 15 wt \% of $C B$ on the mechanical, electrical, thermal and morphology properties were investigated. The results showed that the flexural strength and modulus reduced as increasing of PS content in PS/ABS/CB CPCs. The storage modulus and transition temperature $\left(T_{g}\right)$ of $P S / A B S / C B C P C$ s decreased with increasing of PS content. The PS/ $A B S / C B C P C s$ at blend ratio of 50:50 showed the highest thermal stability compared to 20:80 and 80:20 at same filler loading.
\end{abstract}

Keywords: polystyrene, acrylonitrile butadiene styrene, carbon black, conductive polymer composites

\section{INTRODUCTION}

Conductive polymer composites (CPCs) are composites that consisting of conductive filler and a transition occur from insulating polymer to electrically conductive polymer. ${ }^{1}$ Recently, some level of electrical conductive materials including antistatic materials, electrostatic discharge (ESD) dissipation and electromagnetic interference (EMI) shielding were satisfied by adding conductive filler into polymer matrix. ${ }^{2-4}$ The common conductive fillers of CPCs included 
carbon black $(\mathrm{CB})^{5-7}$, graphite $(\mathrm{G})^{8,9}$, carbon fibre ${ }^{10}$, metal powder and intrinsically conductive polymer (e.g., polyaniline [PAN]). ${ }^{11-13}$

CPCs have many advantages compared to conductive materials, like metals, in term of corrosion resistivity, adaptability to application need, weight, processability and cost. In addition, $\mathrm{CB}$ has a significant cost advantage compared to highly conductive materials (e.g., carbon nanotubes). CB was also showed chemical stability and weight advantage over metallic fibers, flakes and powder. ${ }^{6}$ Besides, CB has good electrical conductivity and mechanical characteristic compared to PAN..$^{9,11,12}$ Therefore, $\mathrm{CB}$ is one of the most promising electrical conductive filler.

Percolation threshold was the critical amount of conductive filler required to form continuous conductive pathway and impart electrical conductivity to the polymer matrix. ${ }^{14}$ Many simple binary composites had a percolation threshold around $15 \%$ filler as predicted by classical percolation theory for random system..$^{14,15}$ The percolation threshold had already been successfully reduced using ternary composites system in which conductive filler had been added into a mixture of two immiscible polymer blend. ${ }^{15}$ Regarding to literature study, conductive filler were enable to form conductive pathway (percolation) within the immiscible polymer blend, either by locating the conductive filler at the interface of a co-continuous structure or in the matrix component. ${ }^{16}$ This condition is called "Double Percolation Concept". In CB filled CPCs, it was desirable to reduce percolation threshold as low as possible to achieve a great conductivity CPCs. ${ }^{5,9,14}$ This situation can also provide better mixture processability and avoid poor mechanical properties that caused by high filler content.

This paper was aim to investigate the mechanical, electrical, thermal and morphology properties of PS/ABS/CB CPCs at different blend ratio.

\section{EXPERIMENTAL}

\subsection{Materials}

PS resin (grade MS500) was supplied by Petrochemicals (M) Sdn. Bhd., with a melt flow index (MFI) of $5.0 \mathrm{~g} / 10 \mathrm{~min}$ at $200^{\circ} \mathrm{C}$. ABS resin was supplied by Idemitsu (M) Sdn. Bhd. with styrene (61\%), acrylonitrile (27\%) and butadiene (12\%). Electrically conductive CB (Conductex@ K Ultra) was supplied by Connell Bros Company LTD. It was in bead form with the particles size of $18 \mathrm{~nm}$. 


\subsection{Sample Preparation}

$\mathrm{PS} / \mathrm{CB}$ and $\mathrm{PS} / \mathrm{ABS} / \mathrm{CB}$ CPCs was prepared by using Brabender ${ }^{\circledR}$ Plastrograph internal mixer. The $\mathrm{PS} / \mathrm{CB}$ and $\mathrm{PS} / \mathrm{ABS} / \mathrm{CB}$ CPCs were mixed according to formulation as shown in Table 1. The compounding was carried out by using counter rotating screw mode at $180^{\circ} \mathrm{C}$ and $50 \mathrm{rpm}$ rotor speed. All formulated PS/CB and PS/ABS/CB CPCs were compressed in sheet form by using compression molding machine, Model GT7014A. The compression sequences involved preheated compound at temperature of $180^{\circ} \mathrm{C}$ for $3 \mathrm{~min}$, followed by compression under pressure of $100 \mathrm{~kg} \mathrm{~cm}^{-3}$ for $3 \mathrm{~min}$ at the same temperature and cooling under pressure for $3 \mathrm{~min}$.

\subsection{Characterisation}

\subsubsection{Flexural test}

The specimens were cut from the compressed sheet and it was in rectangular bar with dimension of $127 \times 12.7 \times 3 \mathrm{~mm}$. Flexural tests were performed by using Instron universal, Model 5569 according to ASTM D790. The flexural strength and flexural modulus of CPCs can be obtained from the flexural tests. Across head speed of $5 \mathrm{~mm} \mathrm{~min}^{-1}$ was used and the loading were $50 \mathrm{kN}$.

\subsubsection{Surface resistivity (SR) measurement}

The SR of PS/ABS/CB CPCs was measured by using four point probes based on ASTM D257. The SR measurement was done on five difference locations on the sample sheet and the mean of the SR value were recorded.

\subsubsection{Dynamic mechanical analysis (DMA)}

The DMA analysis was evaluated by using dynamic mechanical analyser, Model DMA 7e by Perkin-Elmer. DMA was used to determine the tan delta (tan $\delta)$ of CPCs which is the dynamic properties due to the polymer viscous-elastic behaviour at different temperature condition. The sample dimension was $50 \times 10$ $\times 1 \mathrm{~mm}$ and it was tested at constant frequency of $1 \mathrm{~Hz}$ using three point modes at temperature range of $35^{\circ} \mathrm{C}$ to $130^{\circ} \mathrm{C}$. The heating rate used was $10^{\circ} \mathrm{C} \mathrm{min}^{-1}$. 


\subsubsection{Thermogravimetric analysis (TGA)}

The TGA analysis was carried out by using TGA Diamond, Perkin-Elmer apparatus. The $\mathrm{CPCs}$ was heated from $30^{\circ} \mathrm{C}$ to $850^{\circ} \mathrm{C}$ at heating rate of $20^{\circ} \mathrm{C} \mathrm{min}{ }^{-1}$ under nitrogen atmosphere condition with the nitrogen flow rate of $50 \mathrm{ml} \mathrm{min}^{-1}$.

\subsubsection{Scanning electron microscopy (SEM) analysis}

The fracture surface and CB-CB network of CPCs specimens were analysed by using JEOL JSM-6460 LA, at a voltage of $5 \mathrm{kV}$. Specimens were coated with a thin layer of palladium for conductivity purpose.

\section{RESULTS AND DISCUSSION}

\subsection{Flexural Properties}

Figure 1 shows the effect of PS content on flexural strength of PS/ABS/ CB CPCs at $15 \mathrm{wt} \%$ of CB loading. The addition of PS content in the composites has resulted in decreasing of the flexural strength at the fixed $\mathrm{CB}$ loading. The increasing of PS content in PS/ABS/CB due to reduction of plasticity in PS/ABS/ CB CPCs since the PS structure consisting of larger side group such as styrene group. ${ }^{17}$ Figures $2(\mathrm{a}-\mathrm{c})$ show the SEM micrographs of flexural fracture surface for $\mathrm{PS} / \mathrm{ABS} / \mathrm{CB} \mathrm{CPCs}$ at blend ratio of 80/20/15, 50/50/15 and 40/60/15, respectively. It can be observed that the fracture tear lines (black line) in sample 80/20/15 and $50 / 50 / 15$ are propagated across the sample when the flexural load was applied. The fracture tear lines in sample with blend ratio of 40/60/15 were longer. It is believed that the fracture tear lines have stopped propagated by the butadiene particle in ABS when ABS contents are lower which has brought to higher flexural strength. 


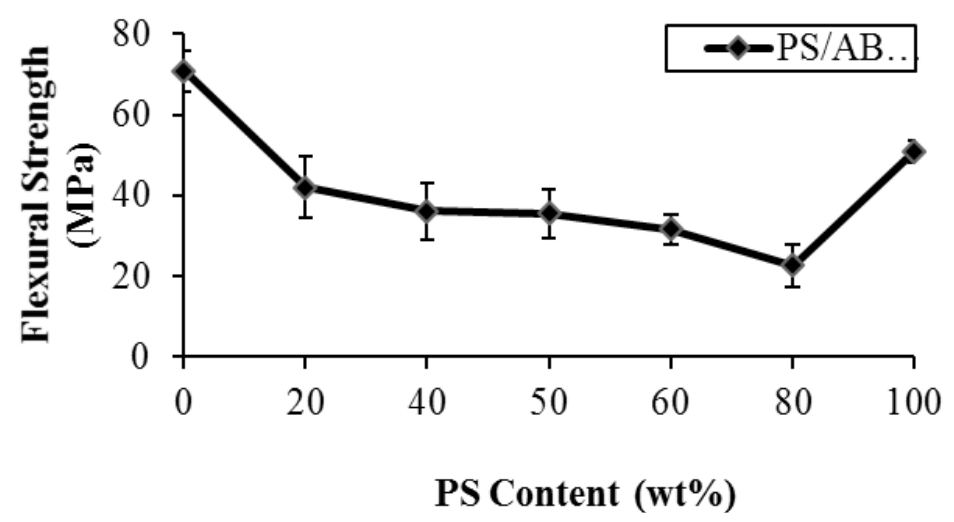

Figure 1: The effect of PS content on flexural strength of $15 \mathrm{wt} \% \mathrm{CB}$ filled PS/ABS CPCs.
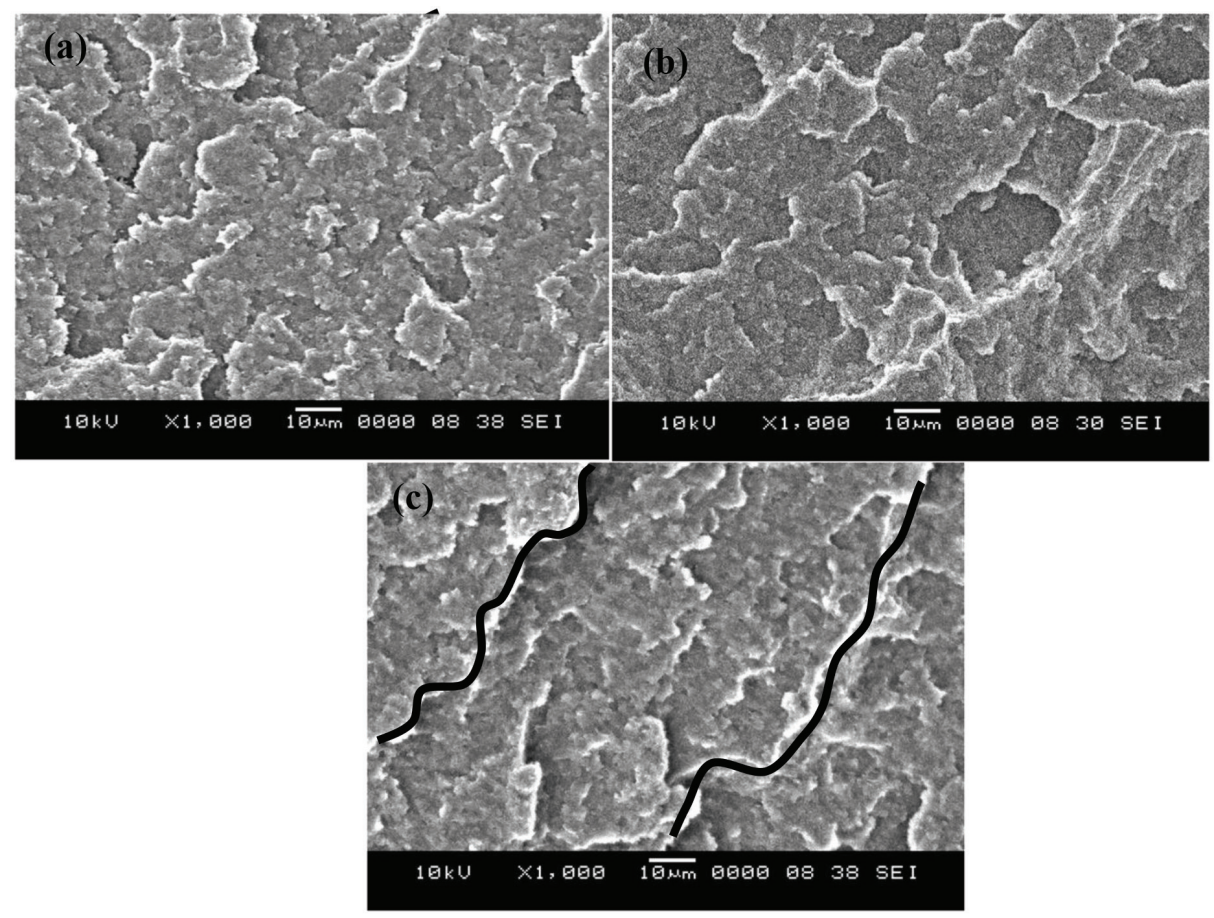

Figure 2: SEM micrograph of $\mathrm{PS} / \mathrm{ABS} / \mathrm{CB} \mathrm{CPCs}$ at blend ratio of (a) 80/20/15, (b) $50 / 50 / 15$ and (c) $40 / 60 / 15$.

The flexural modulus of $\mathrm{PS} / \mathrm{ABS} / \mathrm{CB}$ with different blend ratio is shown in Figure 3. The result indicated flexural modulus was decreased as the increasing of PS content. The decreasing of flexural modulus was due to the ABS used in this research has of higher flexural modulus compared to PS resulting increased 
the rigidity and brittleness of blend system. A similar observation was found by Chiu et al. ${ }^{18}$ in their study of toughening behaviour in CB filled propylene-ethylene block copolymer and styrene-ethylene butylenes-styrene tri-block copolymer.

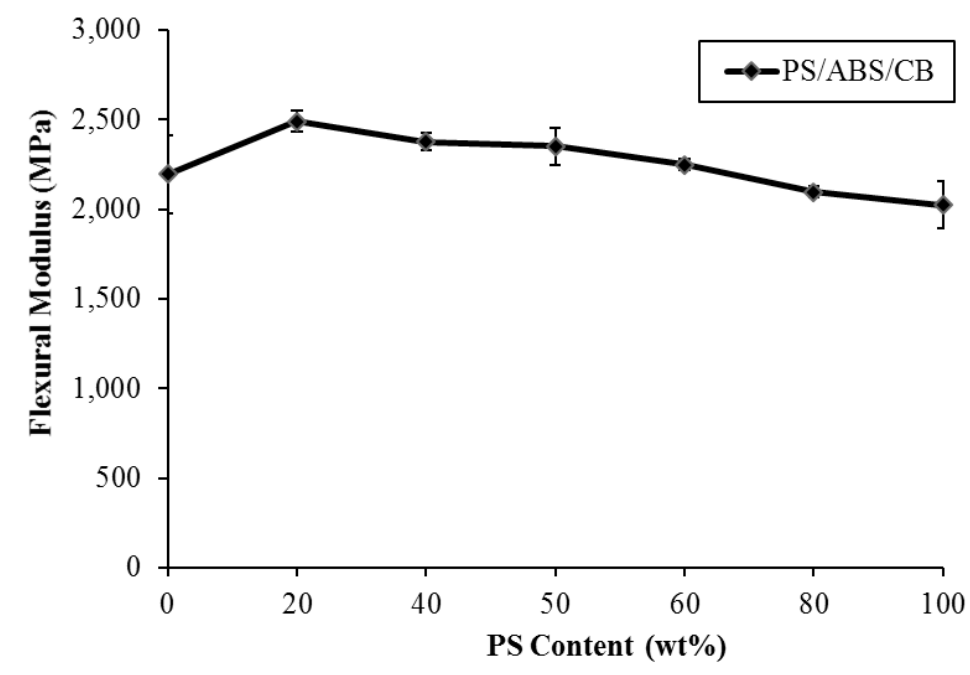

Figure 3: The effect of PS content on flexural modulus of $15 \mathrm{wt} \% \mathrm{CB}$ filled PS/ABS CPCs.

\subsection{SR}

Figure 4 illustrates the effect of PS content on SR of $15 \mathrm{wt} \% \mathrm{CB}$ filled PS/ABS blend. The U-shaped curve relationship is similar to the results that demonstrate typical double percolation characterised by subsequent insulatorconductor-insulator transition as a function of matrix blending ratio meaning that the heterogeneous distribution of $\mathrm{CB}$ composite conductivity in spite of the conduction level. ${ }^{19}$ The SR of PS/ABS/CB decreases rapidly as increasing of PS content. At the PS content increased to $40 \%$ and $50 \%$ by weight, the PS/ABS/CB CPCs are conductive. PS/ABS (50:50) CPCs exhibited the lowest SR compared to other blend ratio. This has proven that $\mathrm{CB}$ has distributed within the co-continuous phase of PS/ABS blend. Further increased in PS content from 60 to $80 \mathrm{wt} \%$ shows the increasing of SR due to the transition from co-continuous to sea island phase was formed in PS/ABS blends.

According to $\mathrm{Yu}$ et al.' ${ }^{19}$ study on ethylene vinyl alcohol (EVA)/low density polyethylene (LDPE), 20/80 to 50/50 presented low resistivity with 18 $\mathrm{wt} \% \mathrm{CB}$ content in percolation threshold curve. Double percolation was happened in EVA/LDPE (50/50). By mean of double percolation effect, CB was distributed in LDPE phase of EVA/LDPE co-continuous blend due to good affinity between 
EVA. Wu et al. ${ }^{20}$ were reported the addition of $\mathrm{CB}$ in $\mathrm{ABS} /$ polyamide 6 (PA6) leads to a phase transition from a sea-island structure to a co-continuous with decreasing of PA6 content.

Besides that, Tchoudakov et al. ${ }^{21}$ have reported the conductivity of high impact polystyrene (HIPS)/styrene isoprene styrene (SIS)/CB determined by blend continuity. At HIPS/SIS/CB (55/45/4), double percolation was occurred where CB was more dominant in HIPS phase and HIPS/SIS was in co-continuous phase.

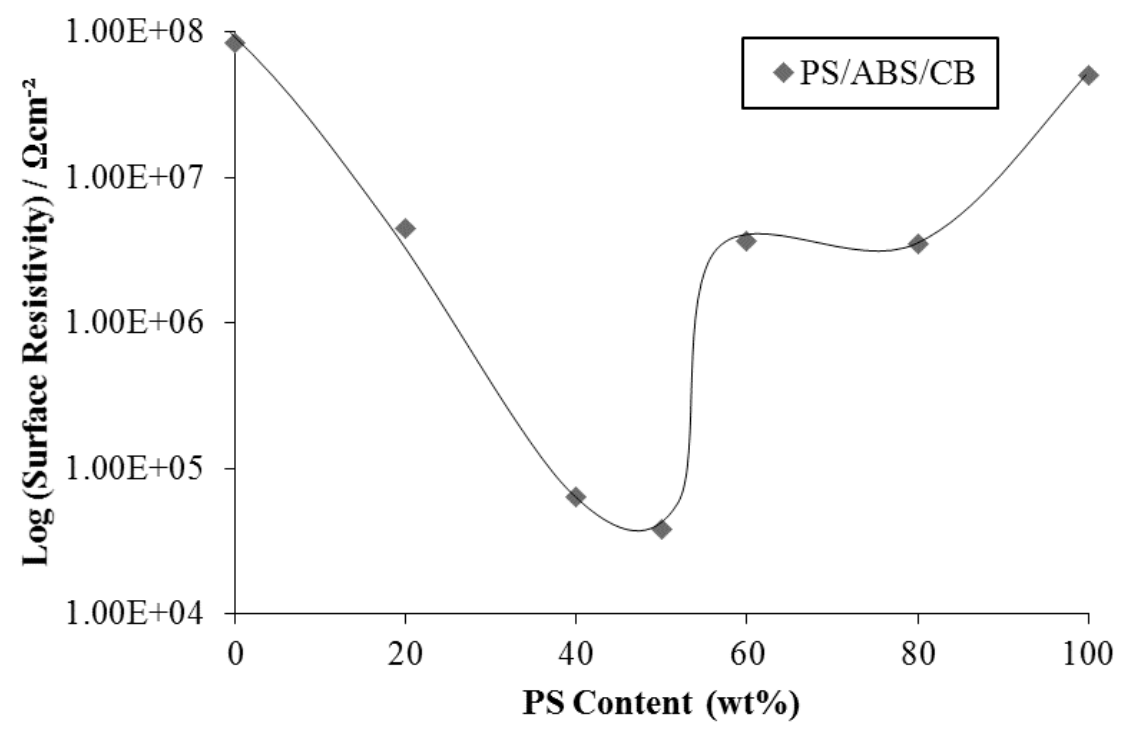

Figure 4: The effect of PS content on SR of PS/ABS/CB CPCs.

\subsection{Dynamic Mechanical Analysis (DMA)}

Figure 5 shows the storage modulus of CB filled PS/ABS blends with various PS concentrations. The storage modulus at temperature of $40^{\circ} \mathrm{C}$ and transition temperature $\left(T_{g}\right)$ are summarised in Table 1 . The storage modulus was decreased with increasing of PS content. As discussed earlier, ABS used in this study has slightly higher flexural modulus than PS, this mean that ABS is more rigid than PS. ABS is copolymer that consists of styrene-acrylonitrile grafted on polybutadiene. Both the ratio of monomer and molecular structure are strongly affected the properties of the copolymer. This observation is in line with flexural modulus result as discussed earlier. Chen et al..$^{22}$ have reported the storage modulus of isotactic polypropylene (iPP)/polyethylene (PE) increased as decreasing of PE content due to the storage modulus of iPP was higher than PE. Besides, the storage 
modulus of neat PE was evidently lower than that iPP/PE blends. Its implies that the higher thermal stability of iPP as compared to PE resulted in the storage modulus of neat PE being evidently lower than that of iPP/PE blends.

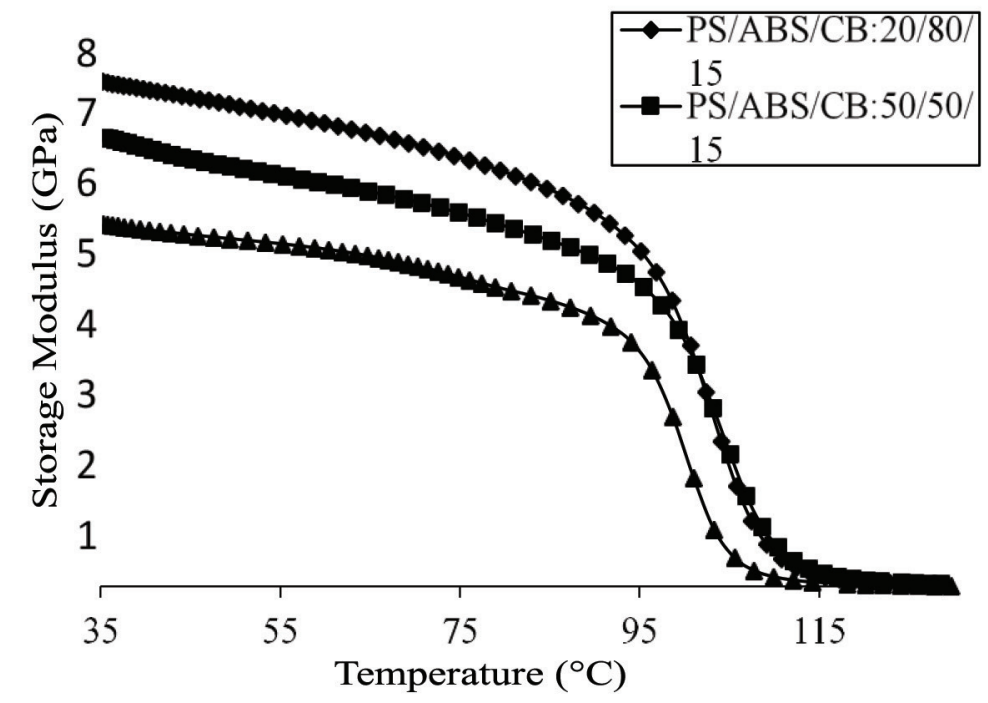

Figure 5: The effect of PS content on storage modulus of PS/ABS/CB CPCs.

In Figure 6, it can be observed that there is a single peak in the entire PS/ ABS blend ratio. This is because both the PS and ABS polymer having the closer $T_{g}$ value which is $111^{\circ} \mathrm{C}$ for PS and $110^{\circ} \mathrm{C}$ for ABS. ${ }^{23}$ At high PS content, the $T_{g}$ was slightly lower due to the decreasing of ABS content since the ABS has slightly higher modulus than PS and caused the blend system become more plasticity. The $\mathrm{PS} / \mathrm{ABS} / \mathrm{CB}(50 / 50 / 15) \mathrm{CPCs}$ exhibited the highest $T_{g}$ compared to others blends due the CB-CB network formed within the PS and ABS phase and these CB-CB network were restricted the chain mobility as well as increased the rigidity of PS/ $\mathrm{ABS} / \mathrm{CB} \mathrm{CPCs}$.

Table 1: The storage modulus at temperature of $40^{\circ} \mathrm{C}$ and glass $T_{g}$ of PS/ABS/CB CPCs with different PS content.

\begin{tabular}{lcc}
\hline Material & $\begin{array}{c}\text { Storage modulus at temperature } \\
40^{\circ} \mathrm{C}(\mathrm{GPa})\end{array}$ & $\begin{array}{c}\text { Glass transition temperature, } T_{g} \\
\left({ }^{\circ} \mathrm{C}\right)\end{array}$ \\
\hline PS/ABS/CB: $20 / 80 / 15$ & 7.7 & 112 \\
PS/ABS/CB: $50 / 50 / 15$ & 6.2 & 114 \\
PS/ABS/CB: $80 / 20 / 15$ & 5.7 & 110 \\
\hline
\end{tabular}




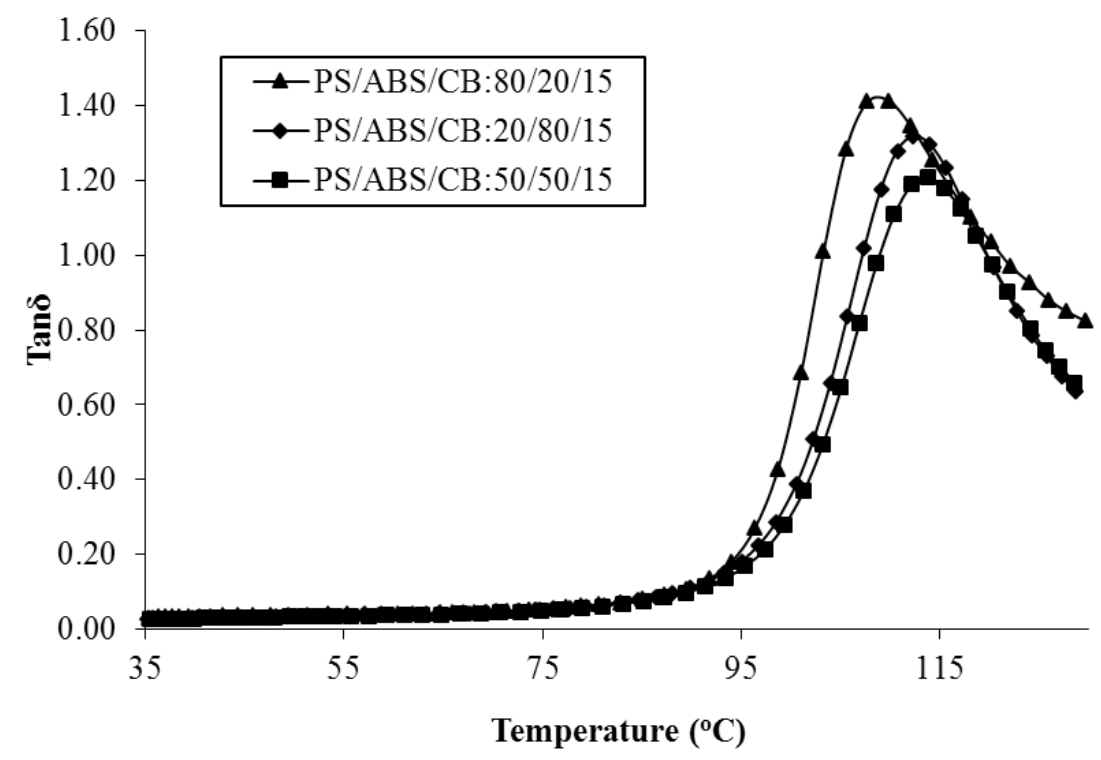

Figure 6: The effect PS content on $T_{g}$ of PS/ABS/CB CPCs.

\subsection{TGA}

The TGA curves of PS/ABS/CB CPCs at 15 wt \% CB loading with different PS content is shown in Figure 7. The TGA data is summarised in Table 2. According to Table 2, the PS/ABS/CB (50/50/15) showed highest temperature at $5 \%$ of weight loss $\left(T_{\mathrm{d} 5 \%}\right)$ and temperature at degradation peak $\left(T_{\mathrm{deg}}\right)$ among all the PS/ABS/CB CPCs. This means that PS/ABS/CB (50/50/15) CPCs has better thermal stability. This might be due to the co-continuous phase presence in $\mathrm{PS} / \mathrm{ABS} / \mathrm{CB}(50 / 50 / 15) \mathrm{CPC}$, where the $\mathrm{CB}$ particles located within PS/ABS interphase. Those $\mathrm{CB}$ providing physical barrier properties to hinder the diffusion of free radial, as a result the thermal degradation of PS/ABS matrix was delayed. ${ }^{24}$ However, PS/ABS/CB (20/80/15) and PS/ABS/CB (80/20/15) was in sea-island phase. The $\mathrm{CB}$ might be dispersed in continuous phase and it enhanced the thermal stability of that polymer phase. In other hand, another discontinuous phase with less $\mathrm{CB}$ will be easier to undergo thermal degradation. Therefore, PS/ABS/CB (50/50/15) with co-continuous phase was higher thermal stability than PS/ABS/ CB (20/80/15) and PS/ABS/CB (80/20/15) with sea-island phase. 


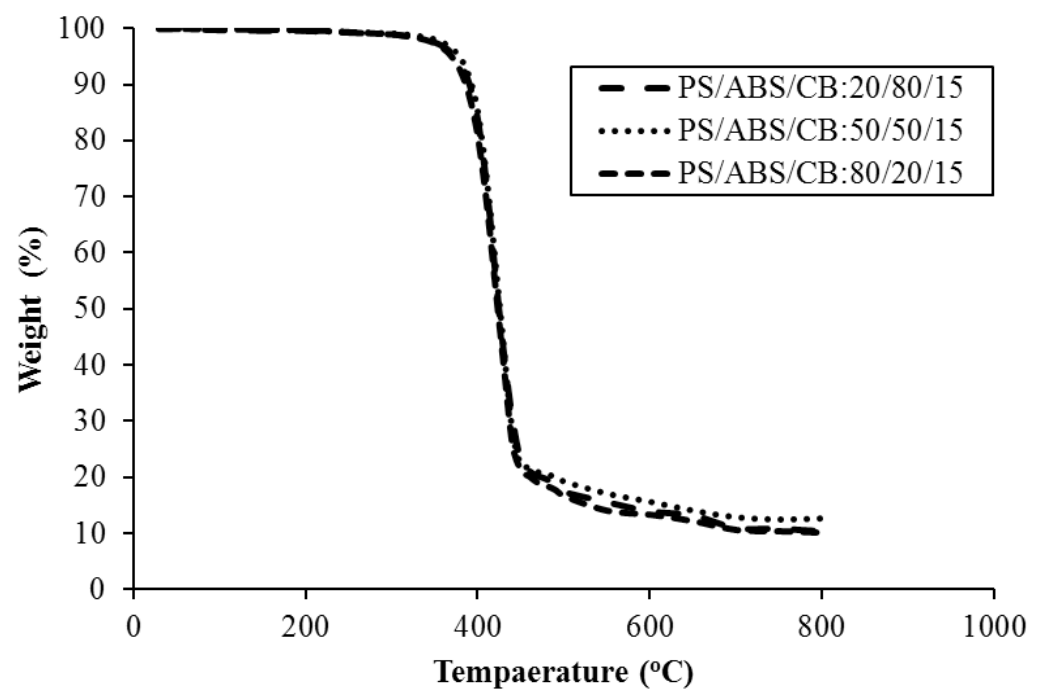

Figure 7: TGA curve of PS/ABS/CB CPCs with different PS content.

Table 2: Temperature at $5 \mathrm{wt} \%$ weight loss $\left(T_{\mathrm{d} 5 \%}\right)$ and temperature at maximum degradation $\left(T_{\text {deg }}\right)$ of PS/ABS/CB CPCs with different PS content.

\begin{tabular}{lcc}
\hline Materials & $\mathrm{T}_{\mathrm{d} 5 \%}\left({ }^{\circ} \mathrm{C}\right)$ & $\mathrm{T}_{\mathrm{deg}}\left({ }^{\circ} \mathrm{C}\right)$ \\
\hline PS/ABS/CB $(20 / 80 / 15)$ & 374 & 421 \\
PS/ABS/CB $(50 / 50 / 15)$ & 378 & 429 \\
PS/ABS/CB (80/20/15) & 370 & 425 \\
\hline
\end{tabular}

\section{CONCLUSION}

PS/ABS/CB CPCs with higher PS content exhibit lower flexural strength and modulus. Besides, the U-shape curve was observed in SR result due to the different of PS/ABS blend ratio caused the PS/ABS/CB (50/50/15) exhibited lowest SR compared to others blend. The DMA result illustrated the storage modulus and $T_{g}$ reduced with increasing of PS content. Moreover, the PS and ABS has almost similar $T_{g}$ was resulted single peak observed in DMA result. However, PS/ABS/ CB $(50 / 50 / 15)$ exhibits the highest $T_{g}$ compared to PS/ABS/CB (20/80/15) and PS/ $\mathrm{ABS} / \mathrm{CB}(80 / 20 / 15)$. For TGA analysis, the PS/ABS/CB (50/50/15) had higher thermal stability than PS/ABS/CB (20/80/15) and PS/ABS/CB (80/20/15) CPCs. 


\section{REFERENCES}

1. Ghosh, P. (2008). Polymer science and technology: Plastics, rubbers, blends and composites. Noida, India: Tata McGraw-Hill.

2. Yu, J., Zhang, L. Q., Rogunova, M., Summers, J., Hiltner, A. \& Baer, E. (2005). Conductivity of polyolefins filled with high-structure carbon black. J. Appl. Polym. Sci., 98(4), 1799-1805, https://doi.org/10.1002/ app.22238.

3. Gupta, A. \& Choudhary, V. (2011). Electromagmetic interference shielding behavior of poly(trimethylene terephthalate)/multi-walled carbon nanotube composites. Compos. Sci. Technol., 71(13), 1563-1568, https://doi.org/10.1002/app.30183.

4. Kumar, S., Lively, B., Sun, L. L., Li, B. \& Zhong, W. H. (2010). Highly dispersed and electrically conductive polycarbonate/oxidized carbon nanofiber composites for electrostatic dissipation applications. Carbon, 48(13), 3846-3857, https://doi.org/10.1016/j.carbon.2010.06.050.

5. Al-Saleh, M. H. \& Sundararaj, U. (2008). An innovative method to reduce percolation threshold of carbon black filled immiscible polymer blends. Composites. Part A, 39, 284-293, https://doi.org/10.1016/j. compositesa.2007.10.010.

6. Al-Saleh, M. H. \& Sundararaj, U. (2008). Nanostructured carbon black filled polypropylene/polystyrene blends containing styrene-butadiene-styrene copolymer: Influence of morphology on electrical resistivity. Eur. Polym. J., 44(7), 1931-1939, https://doi.org/10.1016/j.eurpolymj.2008.04.013.

7. Chen, Y., Li, J., Tan Y., Zhang, K., Shi, Y., Wu, H., Guo, S. \& Wang, M. (2018). Low magnetic field-induced morphological regulation in isotactic polypropylene/poly(e-caprolactone)/carbon black composites for high electrical conductivity and conductive anisotropy. Compos. Commun., 9, 58-62, https://doi.org/10.1016/j.coco.2018.06.002.

8. Chen, G., Lu, J. \& Wu, D. (2007). The electrical properties of graphite nanosheet filled immiscible polymer blend. Mater. Chem. Phys., 104(2-3), 240-243, https://doi.org/10.1016/j.matchemphys.2007.01.011.

9. Thongruang, W., Spontak, R. J. \& Balik, C. M. (2002). Bridges double percolation in conductive polymer composites: an electrical conductivity, morphology and mechanical property study. Polym., 43(13), 3717-3725, https://doi.org/10.1016/S0032-3861(02)00180-5.

10. Cakmak, G., Kucukyavuz, Z., Kucukyavuz, S. \& Cakmak, H. (2004). Mechanical, electrical and thermal properties of carbon fiber reinforced poly(dimethylsiloxane)/polypyrrole composites. Composites. Part A, 35(4), 417-421, https://doi.org/10.1016/j.compositesa.2003.11.006. 
11. Tabellout, M., Fatyeyeva, K., Baillif, P. Y., Bardeau, J. F. \& Pud, A. A. (2005). The influence of the polymer matrix on the dielectric and electrical properties of conductive polymer composites based on polyaniline. $J$. Non-Cryst. Solids, 351(33-36), 2835-2841, https://doi.org/10.1016/j. jnoncrysol.2005.04.085.

12. Jia, Q. M., Li, J. B., Wang, L. F., Zhu, J. W. \& Zheng, M. (2007). Electrically conductive epoxy resin composites containing polyaniline with different morphologies. Mater. Sci. Eng. A, 448(1-2), 356-360, https://doi.org/10.1016/j.msea.2006.09.065.

13. Jia, W., Tchoudakov, R., Segal, E., Joseph, R., Narkis, M. \& A.Siegmann. (2003). Electrically conductive composites based on epoxy resin with polyaniline-DBSA fillers. Synth. Met., 132(3), 269-278, https://doi. org/10.1016/S0379-6779(02)00460-5.

14. Cui, L., Zhang, Y., Zhang, Y., Zhang, X. \& Zhou, W. (2007). Electrical properties and conductive mechanism of immiscible polypropylene/ Novolac blends filled with carbon black. Eur. Polym. J., 43(12), 50975106, https://doi.org/10.1016/j.eurpolymj.2007.08.023.

15. Zhang, Q. -H., \& Chen, D. J. (2004). Percolation threshold and morphology of composites of conducting carbon black/polypropylene/ EVA. J. Mater. Sci., 39(5), 1751-1757, https://doi.org/10.1023/ B:JMSC.0000016180.42896.0f.

16. Planteck, J. \& Wypych, G. (2007). Handbook of antistatics. Ontario: ChemTee Publishing.

17. Luo, S, Chen, Y, Sha, Y., Xue, G, Zhuravleva, E., Schick, C., Wang, X., Zhou, D. \& Li, L. (2018). Molecular weight and interfacial effect on the kinetic stabilization of ultrathin polystyrene films. Polym., 134(3), 204210, https://doi.org/10.1016/j.polymer.2017.11.075.

18. Chiu, H. T. \& Chiu, W. M. (1998). The toughening behavior in propyleneethylene block copolymer filled with carbon black and styrene-ethylene butylene-styrene triblock copolymer. Mater. Chem. Phys., 56(2), 108-115, https://doi.org/10.1016/S0254-0584(98)00143-6.

19. Yu, G. \& Zhang, M. Q. (1999). Conductive polymer blends filled with carbon black: Positive temperature coefficient behavior. Polym. Eng. Sci., 39(9), 1678-1688, https://doi.org/10.1002/pen.11562.

20. Wu, G., Li, B., \& Jiang, J. (2010). Carbon black self-networking induced co-continuity of immiscible polymer blends. Polym., 51(9), 2077-2083, https://doi.org/10.1016/j.polymer.2010.03.007.

21. Tchoudakov, R., Breuer, O. \& Narkis, M. (1997). Conductive polymer blends with low carbon black loading: high impact polystyrene/ thermoplastic elastomer (styrene-isoprene-styrene), Polym. Eng. Sci., 37(12), 1928-1934, https://doi.org/10.1002/pen.11843. 
22. Chen, J. H., Zhong, J. C., Cai, Y. H., Su, W. B. \& Yang, Y. B. (2007). Morphology and thermal properties in the binary blends of poly(propylene-co-ethylene) copolymer and isotactic polypropylene with polyethylene. Polym., 48(10), 2946-2957, https://doi.org/10.1016/j. polymer.2007.03.037.

23. Ibrahim, B. A. \& Kadum, K. M. (2010). Influence of polymer blending on mechanical and thermal properties. Mod. Appl. Sci., 4(9), 157-161, https://doi.org/10.5539/mas.v4n9p157.

24. Chrissafis, K., \& Bikiaris, D. (2011). Can nanoparticles really enhance thermal stability of polymers? Part I: An overview on thermal decomposition of addition polymers. Thermochim. Acta, 523(1-2), 1-24, https://doi.org/10.1016/j.tca.2011.06.012. 